Artigo

\title{
Quando os ritmos corporais dos pedestres nos espaços públicos urbanos revelam ritmos da urbanização
}

\author{
When the pedestrians' body rhythms in urban public \\ spaces disclose rhythms of urbanization
}

Fraya Frehse*

\begin{abstract}
Resumo: Cabe evidenciar duas contribuições metodológicas da ritmanálise de Henri Lefebvre para o problema de como sociedade se transforma pela mediação de práticas sociais que se (re)produzem nos e através dos objetos e espaços mais ou menos tecnológicos que povoam a vida cotidiana em cidades impactadas pela possibilidade da modernidade. Elucidarei primeiramente a ritmanálise, e sua articulação com o pensamento lefebvriano. Virá à tona então a peculiaridade teórica de meu argumento, cuja pertinência empírica demonstrarei brevemente na sequência. Recorrendo a dados fotográficos e etnográficos de minha pesquisa sobre as ruas e praças públicas do perímetro historicamente mais antigo da São Paulo atual (Frehse, 2011), demonstrarei o que corpos humanos que passam ou se deixam ficar fisicamente com regularidade ali revelam sobre o ritmo das mudanças socioculturais nessa megacidade atualmente $-\mathrm{e}$, assim, sobre a ritmanálise como via de apreensão empírica de indícios da mudança social possível na vida cotidiana, no espaço urbano.
\end{abstract}

Palavras-chave: Ritmanálise (Henri Lefebvre). Mudança social. Vida cotidiana. Ritmo. Espaço urbano.

Abstract: I aim to demonstrate two methodological contributions of Henri Lefebvre's rhythmanalysis to the problem of how society transforms itself through the mediation of social practices that (re)produce themselves in and through the more or less technological objects and spaces that are entailed in the everyday life of cities engulfed by the possibility of modernity. First I elucidate rhythmanalysis, and its connection with Lefevre's thought. Hence the theoretical peculiarity of my statement will come to the fore. Its empirical pertinence, though, are briefly shown in the second section. Based on photographic and ethnographic data of my research on the present-day public streets

\footnotetext{
* Doutora em Antropologia Social pela Universidade de São Paulo (USP, São Paulo, Brasil), pósdoutora em Sociologia (da cidade) pela Freie Universität Berlin (Berlim, Alemanha), professora do departamento de Sociologia da Universidade de São Paulo (USP, São Paulo, Brasil) $<$ fraya@usp.br>. Versão revista e atualizada de uma comunicação apresentada no panel "Shaping Life and Life Forms" a convite dos organizadores da Conference "Technospaces. Persistence -Practices - Procedures - Power" que teve lugar na Technische Universität Darmstadt entre 18 e 20 de março de 2015.
}

Civitas, Porto Alegre, v. 16, n. 1, p. 100-118, jan.-mar. 2016 
and squares of the historically oldest São Paulo perimeter (Frehse, 2011), I point out what human bodies that physically cross or stay there on a regular basis may disclose about the rhythm of sociocultural changes in this present-day megacity - and, thus, about rhythmanalysis as a way of empirical apprehension of clues of the social change which is historically possible in the everyday life experienced in urban space.

Keywords: Rhythmanalysis (Henri Lefebvre). Social change. Everyday life. Rhythm. Urban space.

\section{Introdução}

Tendo sido convidada a refletir sobre como a ritmanálise desenvolvida pelo filósofo e sociólogo Henri Lefebvre se deixa articular com a questão de como a técnica e seus espaços "moldam a vida e formas de vida" - título do panel para o qual este ensaio foi concebido -, é inevitável que eu - como estudiosa das implicações metodológicas das ponderações dialéticas desse autor acerca da vida cotidiana no espaço urbano da segunda metade do século 20 -, seja remetida a noções como processo, transformação, história. Nesse sentido, é evidente também que, atenta à influência do método dialético desenvolvido por Karl Marx nas reflexões de Lefebvre sobre o assunto, eu comece por relembrar observações pioneiras de $A$ ideologia alemã acerca da relação dialética entre as dimensões simultaneamente corporal, econômica e social da existência humana (Marx e Engels [1932] 1960, p. 28) e a história da humanidade: assim concebida, a existência humana seria pressuposto da história da humanidade e da humanização do homem - portanto, das transformações históricas deste. Em direção análoga vai a Sociologia de Marx lefebvriana, com sua conceituação da práxis como "ato, relação dialética entre a natureza e o homem, as coisas e a consciência (Lefebvre, [1966] 1974, p. 41$).{ }^{1}$ Todo e qualquer ato humano na vida cotidiana carrega em si a possibilidade de que por sua mediação a vida social seja inovada historicamente, que seja apenas mimetizada ou repetida (Lefebvre, [1966] 1974, p. 47). Em suma, também aqui o assunto é transformação, história.

Ambas as abordagens se prestam bem a pontos de partida para este ensaio por evidenciarem de maneira sintética a consolidação, na sociologia, de uma linhagem de preocupações dialéticas com indícios empíricos de mudança social na vida cotidiana, em cidades engolfadas pela chamada modernidade -

\footnotetext{
${ }^{1}$ São de minha autoria todas as traduções para o português de textos estrangeiros cujos tradutores não aparecerem nas Referências.
} 
termo este empregado para designar um processo histórico de transformações socioculturais relativas ao alcance social da concepção de que tudo e todo são transitórios, moda, "modernos", e que, mais ou menos diretamente tributário da industrialização na Europa Ocidental a partir do século 18, tem tido os seus fundamentos espaciais e temporais colocados mais e mais em xeque neste início de século 21, à medida que se aprofundam justamente nos mais diversos tempos e espaços as contradições socioculturais da chamada economia globalizada. ${ }^{2}$ A questão de fundo que, anunciada por Marx e Engels e aprofundada de maneira ímpar por Lefebvre, ainda permanece contemporânea, é a seguinte: como a sociedade se transforma pela mediação de práticas sociais que se (re)produzem nos e através dos objetos e espaços mais ou menos tecnológicos que povoam o nosso dia a dia, em cidades impactadas pela possibilidade histórica da modernidade? A seu modo, também o panel no âmbito do qual se originou este ensaio ressalta a atualidade da pergunta, preocupado com os modos pelos quais as novas tecnologias moldam a vida e suas formas - 0 que ocorre de modo privilegiado no mundo urbano agitado pelas promessas e agruras da racionalidade implícita no moderno.

Considerando que em particular Lefebvre se devotou não apenas conceitual, mas também metodologicamente ao problema sociológico da mudança social do ponto de vista das contradições da práxis no espaço urbano, o meu objetivo aqui é evidenciar a contribuição que a obra desse sociólogo oferece justamente para uma questão metodológica implícita no problema. Trata-se justamente da ritmanálise, concentrada na diferenciação analítica das sequências de repetições que impregnam e envolvem o corpo humano como espaço "no e pelo" espaço na vida cotidiana. Como esse instrumental pode contribuir para a apreensão empírica das transformações históricas que se insinuam na vida cotidiana nas cidades contemporâneas? Quando, como eu numa pesquisa atualmente em fase de conclusão (Frehse, 2011), se enfoca, nos termos da ritmanálise, os usos atuais das ruas e praças públicas do centro histórico de São Paulo, é possível reconhecer, como espero demonstrar aqui, duas contribuições metodológicas da perspectiva lefebvriana para o problema da investigação empírica de como a mudança social se insinua na vida cotidiana no espaço urbano contemporâneo.

No intuito de desenvolver tal argumento, este ensaio se constitui de três seções. Num primeiro momento elucidarei do que trata, afinal, a ritmanálise, e como ela se articula com a pesquisa acadêmica sobre a obra lefebvriana. Assim se evidenciará a peculiaridade de meu argumento, cuja

\footnotetext{
${ }^{2}$ Para uma síntese do debate sociológico a respeito, ver Costa (2010, p. 26-30).
} 
pertinência empírica demonstrarei na sequência. Para tanto, recorrerei, na segunda seção, a dados empíricos relativos a minha pesquisa sobre São Paulo. Assim se explicitará o título desta exposição. O meu objetivo específico é demonstrar o que corpos humanos que atualmente passam ou se deixam ficar fisicamente com regularidade nas ruas e praças do perímetro historicamente mais antigo da cidade, revelam sobre a dinâmica histórica das mudanças socioculturais nessa megacidade latino-americana do presente.

Assim será possível reconhecer de modo sintético, no terceiro e último momento desta reflexão, que a ritmanálise remete, de um lado, à relevância cognitiva do estranhamento antropológico e histórico dos ritmos corporais tanto do pesquisador quanto dos pedestres que o circundam, nas ruas e praças estudadas, quando interessa apreender analiticamente as possibilidades históricas da mudança sociocultural implícitas na vida cotidiana. Consequentemente e de outro lado, a ritmanálise incentiva a sociologia enfrentar um objeto de pesquisa singular: a historicidade das regras de comportamento corporal nos espaços públicos urbanos.

\section{A ritmanálise no pensamento lefebvriano}

Nos últimos trinta anos de vida, Lefebvre referenciou explicitamente a ritmanálise com relativa constância. Debuta no segundo volume da Critique de la vie quotidienne uma alusão à "ritmologia ou 'ritmanálise' sociológica", ao que segue uma nota de rodapé com a seguinte indicação: "[t]ermo emprestado a Gaston Bachelard" (Lefebvre, 1961, p. 233), que por sua vez, em Dialectique de la durée (Bachelard, 1950), aponta ter assumido a noção do filósofo português Lúcio Alberto Pinheiro dos Santos (Baptista, 2010), para quem a análise de ritmos fisiológicos poderia curar a depressão ou apatia mentais (Meyer, 2008, p. 147). Depois dessa primeira citação na obra lefebvriana, o termo reaparece no mínimo em La production de l'espace ([1974] 2000), em La présence et l'absence (Lefebvre, 1980) e no terceiro volume da Critique de la vie quotidienne (1981). Isso, antes de dois artigos publicados em conjunto com sua última esposa (Lefebvre e Régulier, 1985; [1986] 1992) e o livro póstumo Éléments de Rythmanalyse (Lefebvre, 1992) - que inclui como espécie de excurso o artigo com Cathérine Régulier de 1986-se dedicarem exclusivamente à abordagem. No livro monográfico sobre a ritmanálise, esta é definida como "ciência, um novo domínio do saber: a análise dos ritmos" (Lefebvre, 1992, p. 11). Sequências de repetições diversas, os ritmos poderiam ser investigados de duas maneiras complementares: ou através de uma comparação entre casos concretos, quanto a ritmos corporais (de seres vivos ou não), ou com base 
em noções, categorias abstratas (Lefebvre, 1992, p. 13). E isso em prol de um objetivo que Lefebvre explicitou conjuntamente com Régulier (Lefebvre, Régulier, 1985, p. 191): "Demonstraremos as relações entre a vida cotidiana e os ritmos, isto é, as modalidades concretas da vida social". O intuito traduzse num objeto investigativo específico: "exclusivamente o aspecto rítmico do tempo cotidiano". O foco direciona-se, portanto, para as relações que impregnam e envolvem o corpo humano, como espaço "no e pelo" espaço (Lefebvre, [1974] 2000, p. 199); mas relações entre as sequências de repetições cíclicas (que provêm historicamente dos mundos natural e corporal) e aquelas de caráter linear (advindas do mundo racional e técnico) que perfazem os ritmos dessa seara específica da realidade humana que é a vida cotidiana (Lefebvre, 1992, p. 18).

O ponto de reparo para tudo isso é, com efeito, a noção de vida cotidiana como "nível da realidade social" que Lefebvre inquiriu ao longo de toda a sua trajetória intelectual. Sendo o "lado ao mesmo tempo mais evidente e mais indiscernível da prática social, em que a banalidade e a profundidade coexistem, pois se trata da existência e [d]o 'vivido' não transcritos especulativamente" (Lefebvre, [1947] 1958, p. 56, 52), a vida cotidiana é um produto histórico. Daí que "o cotidiano"é modo de vida historicamente próprio de sociedades cujo dia a dia, com a modernidade, se vê engolfado pelas contradições da programação e do cálculo comandados pelo mercado, pelo sistema das equivalências, o marketing e a publicidade; o que inclui o momento dialético extremo, não menos prenhe de contradições, sinalizado pela "cotidianidade", noção que ressalta a dimensão homogênea, repetitiva, fragmentária da vida cotidiana como sintetizou Lefebvre numa entrevista ao jornal Le Monde (Corpet, [1972] 1989, p. 134). Com efeito, o prefácio do primeiro volume revisto de Critique de la vie quotidienne ([1947] 1958, p. 68) é explícito sobre a existência de um "programa crítico" cujo fundamento é a crítica da alienação no capitalismo do segundo pós-guerra. Em termos teóricos, trata-se de atualizar as reflexões marxianas sobre o assunto para a compreensão da realidade social da segunda metade do século 20. O que equivale a dizer: cabe apreender possibilidades históricas de transformação dessa realidade, em meio à prevalência crescente de mecanismos reprodutivos no cotidiano - dentre os quais, aliás, a própria técnica (Lefebvre, 1967-1971, p. 24).

Como acessar empiricamente os ritmos que impregnam a vida cotidiana? Em Éléments de rythmanalyse, Lefebvre esboça as orientações epistemológicas básicas. A análise depende de se "isolar um ou outro movimento com o seu ritmo no conjunto organizado" (Lefebvre, 1992, p. 27), procedimento que, por sua vez, exige do "ritmanalista" uma atitude definida: fazer de seu corpo 
um metrônomo, parâmetro para a "escuta" dos corpos dos outros em busca da integração recíproca do fora e do dentro desses mesmos corpos observados (Lefebvre, 1992, p. 32). Com efeito, a experiência e o conhecimento do corpo são os fundamentos da ritmanálise, como aparece resumido na conclusão do livro (Lefebvre, 1992, p. 91). Pautado nessas instruções todas, apresentadas nos primeiros dois capítulos da publicação, os cinco restantes e o excurso trazem diferentes exercícios ritmanalíticos acerca de objetos de conhecimento definidos que envolvem o autor em seu dia a dia na Europa do fim do século 20: uma rua parisiense, adestramentos corporais, a mídia, a música, as cidades do Mediterrâneo.

No meu modo de ver, esse enfoque explícito sobre espaços e tempos da vida cotidiana nos anos 1980, por referência ao corpo humano, contribuiu de modo significativo para que os (até agora poucos) autores que, pelo que pude perceber, se aprofundaram na abordagem a reconhecessem essencialmente como contribuição conceitual ao problema da vida cotidiana no mundo capitalista do final do século 20.

Baseando-se nos dois últimos volumes de Critique de la vie quotidienne (1961, 1981), mas também nas três publicações monográficas sobre a ritmanálise anteriormente mencionadas - as quais cotraduziu para o inglês (Lefebvre, 2004) -, o geógrafo Stuart Elden (2004, p. ix-x) enfatiza, em sua introdução a Rhythmanalysis, a importância da abordagem tanto para uma compreensão mais precisa da noção de vida cotidiana (o seu duplo sentido em inglês e em francês) quanto para a reflexão acerca da conjunção e separação entre espaço e tempo. Ademais, enxerga nos três trabalhos específicos sobre a ritmanálise demonstrações da preocupação lefebvriana com o "contraste" entre o sistema capitalista e a vida cotidiana dos indivíduos. Recorrendo, a seu modo, a fontes semelhantes às de Elden, o filósofo Kurt Meyer (2008, p. 147-148), por sua vez, considera que os estudos ritmanalíticos conduzem ao "âmago" da crítica lefebvriana da vida cotidiana; ou seja, "às análises do ordenamento temporal dos ritmos no cotidiano". Estas investigariam a continuidade do tempo rítmico no fluxo temporal linear da sociedade industrial moderna, e as interferências de ambos os tempos. Carlos Fortuna (2012, p. 203-204), enfim, sublinha, com base em Élements de rythmanalyse e em La production de l'espace, o caráter inovador da "conviç̧ão" lefebvriana de que a experiência sensorial na vida cotidiana é indissociável de estímulos externos, do "mundo material dos objetos".

$\mathrm{O}$ meu argumento incide justamente sobre a ênfase dos estudiosos na contribuição conceitual da ritmanálise, discernível em obras específicas de Lefebvre. Quando, diferentemente, se contempla a ritmanálise em conexão 
com as ponderações de natureza teórica e metodológica de Lefebvre acerca de seu modo transdutivo de pensar, e que se encontram dispersas por publicações variadas ao longo das décadas, aí o que vem para o primeiro plano é notadamente o papel metodológico da abordagem para a apreensão de indícios da mudança social historicamente possível na vida cotidiana.

A transdução constitui o fundamento epistemológico da obra de Lefebvre. Mencionada pela primeira vez em Lógica formal, lógica dialética (Lefebvre, [1947] 1983, p. 15), trazida a público no mesmo ano em que apareceu o primeiro volume de Critique de la vie quotidienne (Lefebvre, [1947] 1958), a transdução encontra a sua síntese talvez mais simples no segundo volume da Critique de la vie quotidienne: ela „vai do real (dado) ao possível“, ou seja, constrói um objeto virtual a partir de informações, atingindo a solução a partir dos dados" (Lefebvre, 1961, p. 121). Como marxista dialético, o autor busca sempre as possibilidades históricas da produção de inovações sociais numa realidade que concebe como totalidade aberta e contraditória, e cujos limites de inovação residem justamente em contradições do passado ainda não superadas, e que o presente carrega em si no nível da vida cotidiana. A práxis humana, afinal, é essencialmente contraditória, inovadora, mimética e repetitiva.

À luz dessas referências, há como compreender tanto por que a crítica da vida cotidiana constitui um projeto de vida inteira quanto por que, segundo o amigo Armand Ajzenberg (1994, p. 5), Lefebvre teria considerado Élements de rythmanalyse o quarto tomo de sua crítica da vida cotidiana. Decisivo para o presente ensaio, entretanto, é o fato de que, sendo sociólogo, Lefebvre não se dá por satisfeito com o caráter filosófico da transdução.

Com efeito, a obra do autor expressa também um empenho constante em operacionalizar, em termos metodológicos, o seu modo transdutivo de pensar. Resulta daí em particular o método regressivo-progressivo, que em 1953 foi apresentado pela primeira vez num artigo de periódico (Lefebvre, [1953] 2001), e cujo procedimento Lefebvre, a partir de então, adotou em relação a vários "campos" empíricos de pesquisa: de cidades definidas até o "campo das representações", passando pela produção do espaço (cf. a respeito Frehse, 2014, p. 246). As duas facetas, investigativa e interpretativa, desse método manifestam-se em três procedimentos dialéticos, momentos nos quais se trata, primeiramente, de descrever e, depois, de datar historicamente, em termos analíticos, os elementos materiais e imateriais que estão dados em qualquer campo empírico de pesquisa. O objetivo é identificar as contradições históricas vigentes nessa realidade social para, assim, apontar, em termos explicativos, as possibilidades de mudança social ali. 
Quando se leva em conta essa dimensão metodológica da obra lefebvriana, a ritmanálise se desvela como um saber sobre os ritmos da vida cotidiana que se baseia em um tipo de análise bem definido desse objeto. Os ritmos vigentes em qualquer campo empírico também são datados historicamente, para fins de sua análise. Se, afinal, ritmos cíclicos e lineares são tão fundamentais para a crítica da vida cotidiana, então porque Lefebvre os datou historicamente: repetições cíclicas são pré-capitalistas, e as lineares pressupõem o tempo abstrato, quantitativo dos relógios capitalistas.

Nesse sentido, a ritmanálise é invariavelmente regressivo-progressiva; pressupõe o método regressivo-progressivo. Embora Lefebvre não tenha nunca explicitado essa conexão, fez uso operacional dela em vários momentos de sua obra. A primeira menção à ritmanálise se dá justamente no âmbito de uma reflexão acerca da interação entre tempos e espaços na cotidianidade: a abordagem "se empenha em discriminar periodicidades e estudar suas relações e sobreposições" (Lefebvre, 1961, p. 232-233). Alguns anos mais tarde segue, por sua vez, uma referência indireta ao vínculo entre ambas as abordagens: a "crítica da vida cotidiana" deveria demonstrar "historicamente a constituição e formação da cotidianidade", entre outros "a separação 'homem-natureza'", o deslocamento dos ritmos, o aumento da nostalgia [...], a deterioração do drama, ou melhor, do trágico e da temporalidade" (Lefebvre, 1968, p. 78; grifo meu). Decisivo para a crítica parece ser, entre outros, que aos ritmos subjaz um processo histórico de cuja dinâmica aquela dos próprios ritmos contém indícios. Alguns anos mais tarde a produção do espaço vem para o primeiro plano como um processo histórico central para a modernidade, e a ritmanálise volta a ser mencionada de modo explícito; e novamente em conexão com a apreensão de transformações históricas - no e pelo espaço. Já que "cada corpo vivente é um espaço e tem um espaço: ele se produz ali e o produz", e como "o tempo social se produz e reproduz a través do espaço; mas este tempo social se reintroduz com seus traços e suas determinações; repetições, ritmos, ciclos, atividades", o "saber (a ciência) sobre o uso dos espaços" se liga à "análise dos ritmos, da crítica efetiva dos espaços representativos e normativos". Com efeito, a ritmanálise "completa a exposição [exposé] da produção do espaço" (Lefebvre, [1974] 2000, p. 199, 392, 412 e 465).

No ano de 1980 ganha destaque outro objeto investigativo: as "representações não filosóficas" que emergem na vida cotidiana (Lefebvre, 1980, p. 147-184). Também em prol da apreensão dessas "presenças do ausente" a ritmanálise pode ser útil: ritmos cíclicos subjazem ao uso qualitativo do corpo e, portanto, à presença; ritmos lineares, por sua vez, "só imprimem 
um sentimento de ausência que invade o cotidiano" (Lefebvre, 1980, p. 181). E eis que, no terceiro volume da Critique de la vie quotidienne, a abordagem é reconhecida pela primeira vez como "nova ciência em constituição" (Lefebvre, 1981, p. 130). No entanto, o seu vínculo com a crítica da vida cotidiana como processo histórico se mantém: "É a partir da organização do trabalho-dividido e composto, medido e quantitficado - que a quantificação ganhou a sociedade toda, contribuindo para a realização do modo de produção [...]. O qualitativo quase desapareceu. Mas aqui ainda esse 'quase' tem muita importância” (Lefebvre, 1981, p. 130). O autor reconhece como traço da sociedade contemporânea uma dinâmica específica dos ritmos: "o esmagamento dos ritmos e tempos naturais pela linearidade", situação que engendra uma necessidade de ritmos a qual se expressa nas inovações rítmicas na música e na dança (Lefebvre, 1981, p. 134-35).

Enfim, quatro anos mais tarde, e aparece o primeiro artigo inteiramente devotado ao "projeto ritmanalítico", ao que se seguem os dois outros textos monográficos anteriormente evocados. Se nesse contexto ganham relevo os fundamentos teóricos e metodológicos da ritmanálise, permanece presente na estrutura argumentativa de todos esses trabalhos a associação dos ritmos com determinadas transformações históricas da sociedade capitalista nas cidades.

Tendo-se em conta essa trajetória teórica e metodológica, que aqui apenas esbocei, espero que não seja mais difícil responder a questão da contribuição metodológica da ritmanálise para a apreensão empírica de como as possibilidades de mudança social aparecem na vida cotidiana nas cidades contemporâneas. Justamente a conexão entre a ritmanálise e o método regressivo-progressivo é decisiva. Gostaria de demonstrar brevemente o que os ritmos corporais atuais dos pedestres das ruas e praças públicas do centro de São Paulo desvelam empiricamente a respeito.

\section{Uma breve ritmanálise dos pedestres nos espaços públicos centrais de São Paulo}

Entendendo "urbanização" em termos lefebvrianos, isto é, como conjunto de processos contraditórios que englobam aspectos econômicos, sociais e culturais ligados à expansão geográfica das cidades (Lefebvre, 1970; ver também Schmid, 2005, p. 132), venho enfrentando etnograficamente, nos últimos anos (Frehse, 2011), uma questão bem específica, de inspiração ritmanalítica: Quais características diferentes da urbanização contemporânea vêm para o primeiro plano, quando, como pesquisador "regressivoprogressivo", se faz do próprio corpo um metrônomo nos espaços públicos 
do berço histórico dessa megacidade de quase 12 milhões de habitantes (e que é coração de uma região metropolitana que soma quase 19,7 milhões de moradores)? Refiro-me à postura lefebvriana de fazer do próprio corpo o parâmetro decisivo para a apreensão dos ritmos de outros corpos em prol de uma integração recíproca do fora e do dentro - só que, no caso, em busca de diferenças que a urbanização em São Paulo dos tempos que correm evidencie, por referência à urbanização atual como processo histórico vigente nos quatro cantos do mundo, e que assumo como totalidade aberta e contraditória.

Justamente o estranhamento antropológico das ruas e praças centrais paulistanas resultante de tal postura metodológica já me auxiliara alguns anos antes (Frehse, 2011b) como instrumental para uma pesquisa documental que visou perscrutar sociológica e antropologicamente o advento da modernidade historicamente própria da Europa Ocidental no século 19, numa São Paulo que até meados desta centúria ainda era fortemente rural e escravista, e somava 30 mil habitantes. A ritmanálise regressivo-progressiva dos ritmos corporais dos pedestres nas ruas e largos do mais antigo núcleo urbanizado de São Paulo - atualmente conhecido como Centro Velho, na chamada colina histórica - entre 1808 e 1917, conduziu-me a uma constatação que é central para a questão formulada no parágrafo anterior. $\mathrm{O}$ transeunte, como essência do tipo urbano moderno (com suas variações próprias da Europa ocidental "dandy", "flâneur" etc.) - portanto de um tipo de pedestre com o qual eu me identifico pessoalmente, em termos corporais, nas ruas e praças de qualquer cidade, é uma invenção sociocultural bastante específica, em termos temporais e espaciais. Ao transeunte corresponde um modo bem específico de servir-se de seu corpo em gesto e postura: ele passa fisicamente por ruas e praças. Mas decisiva para a caracterização do transeunte como tipo de pedestre é também que essa "técnica corporal", no sentido de Marcel Mauss ([1936] 1997), transcorre em um ritmo definido, regular - linear -, em conformidade com os ritmos de trabalho e de lazer do transeunte. Em termos ritmanalíticos, o transeunte se particulariza, pois, pela passagem física regular das ruas e praças urbanas.

Ora, do ponto de vista regressivo-progressivo, esse comportamento corporal é inseparável da modernidade oitocentista da Europa ocidental. Em São Paulo, a passagem física regular, ou circulação, pelas ruas e praças, começou a firmar-se como regra de civilidade de alcance empírico crescente a partir dos anos 1880 , com a crise final da escravidão africana no país - tornando-se inclusive, nesse contexto, passível de apreensão fotográfica. 
Figura 1. Plano médio a partir do rés-do-chão sobre a atual Rua 15 de Novembro, 1887

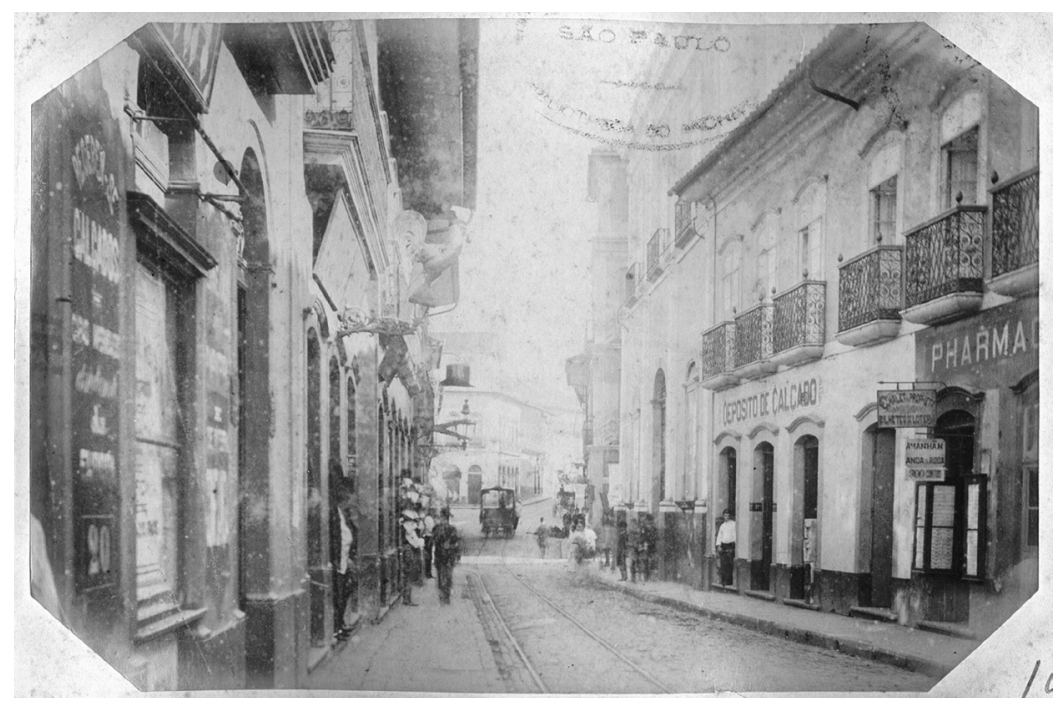

[C Militão Augusto de Azevedo; Fonte: Arquivo do Estado de São Paulo] $]^{3}$

Até então, as ruas e largos paulistanos tinham sido essencialmente lugares de permanência e, dependendo da ocasião, ajuntamento físico regular de determinados tipos de pedestres - sobretudo de gente que, envolvida na labuta e na sociabilidade do trabalho braçal, não raro era flagrada pelas pesadas câmeras fotográficas da época de pé, sentada ou mesmo deitada diante da soleira de alguma porta (figuras 2-3).

Refiro-me a homens, mulheres e crianças cativos, forros ou livres pobres. Já dentre os membros das camadas senhoriais, de grande prestígio social na cidade de então, os ritmos implícitos no conjunto de técnicas corporais nas ruas e São Paulo eram outros: excepcionalidade ou periodicidade na passagem ou ajuntamento físico de homens, mulheres e crianças de elite ali, no âmbito das muitas ocasiões de cunho goffmanianamente cerimonial (Goffman, 1967, p. 54) implícitas nas festividades religiosas e civis episódicas que também pautavam o dia a dia da urbe ainda escravista; para não mencionar o "pagamento" não raro semanal de visitas a parentes ou conhecidos (figura 4).

\footnotetext{
${ }^{3}$ Agradeço ao Arquivo do Estado de São Paulo e aos senhores Jamil Nassif Abib e Apparecido Salatini pela generosidade na cessão das imagens de suas coleções iconográficas para os fins desta publicação.
} 
Figura 2. Plano médio a partir do rés-do-chão sobre rua que atualmente integra a Praça da Sé (c. 1862)

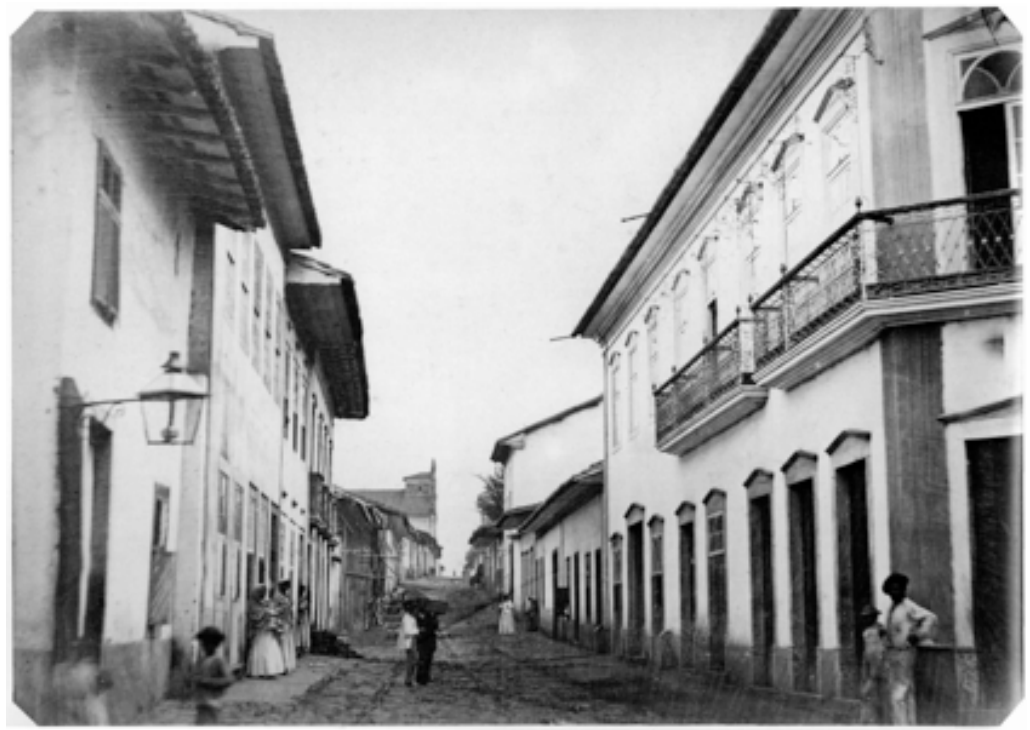

[C Militão Augusto de Azevedo; Fonte: Coleção Jamil Nassif Abib]

Figura 3. Plano aberto a partir do rés-do-chão sobre a atual Rua de São Francisco e de beco da Rua José Bonifácio (c. 1862)

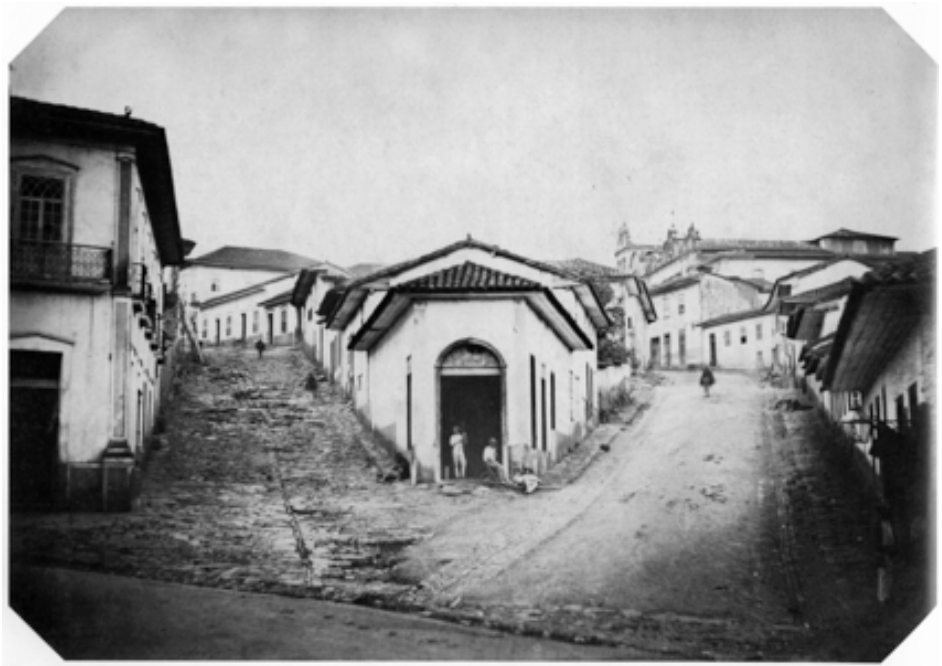

[C Militão Augusto de Azevedo; Fonte: Coleção Jamil Nassif Abib] 
Figura 4. Plano aberto a partir do primeiro andar sobre o atual Pátio do Colégio em dia de festividade cívica (c. 1862)

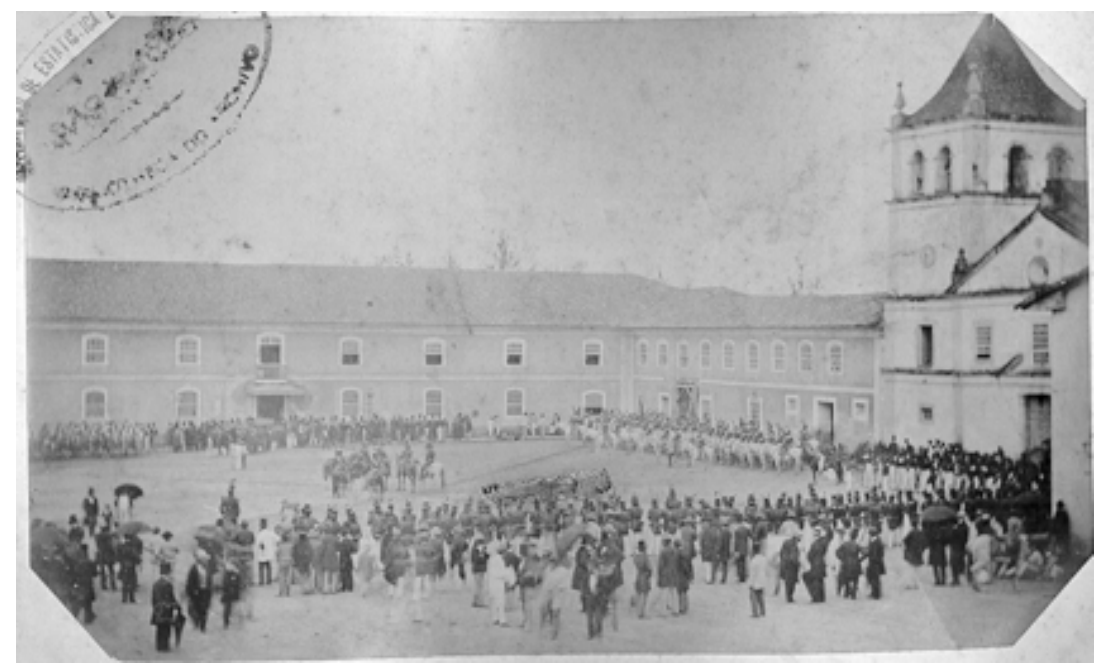

[C Militão Augusto de Azevedo; Fonte: Arquivo do Estado de São Paulo]

Quando, de posse dessas constatações sobre o passado paulistano oitocentista, passei a transitar pelas mesmas ruas e praças do perímetro central da megacidade durante o período comercial dos anos 2010 em busca de indícios do modo como processos históricos se evidenciam na vida cotidiana e, notadamente, apontam para características definidas da urbanização contemporânea em São Paulo, o que estranhei não foram - diferentemente do século 19 - os atualmente numerosos transeuntes ali (figura 5).

O que chamou a minha atenção foi sobretudo a multiplicidade de não-transeuntes. São eles que me desafiam em termos conceituais, quanto a características diferentes da urbanização atual, tendo-se em conta que a bibliografia sociológica sobre o assunto nas metrópoles ocidentais contemporâneas associa em geral ruas a espaços de mobilidade, circulação acelerada de pedestres e veículos (figuras 6-7). 


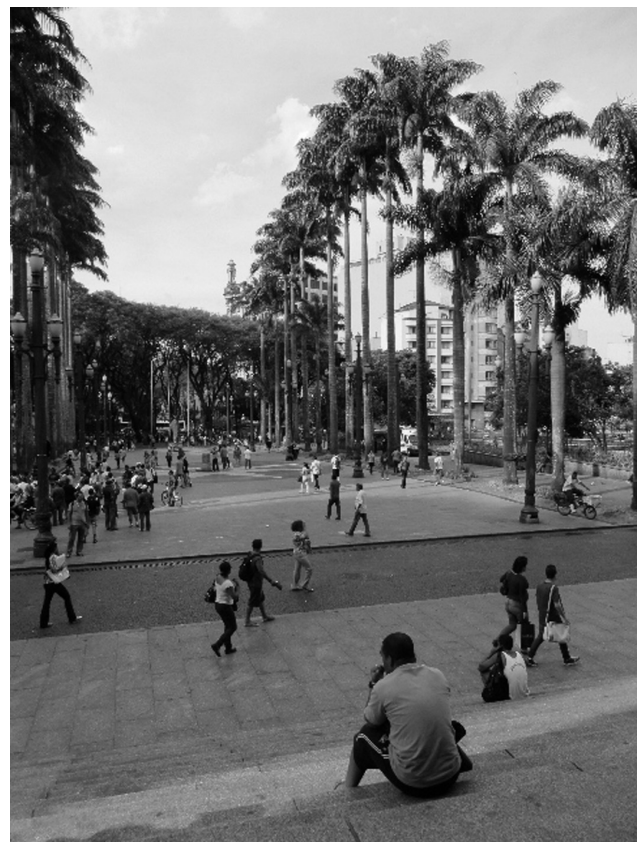

Figura 5. Plano aberto

a partir da escadaria da Catedral da Sé sobre a face nordeste da Praça da Sé (outubro 2013)

[C Fraya Frehse;

Fonte: Coleção Particular]

Figura 6. Plano fechado a partir do rés-do-chão sobre músico de rua da Rua 15 de Novembro (novembro 2012)

[C) Fraya Frehse; Fonte: Coleção Particular]

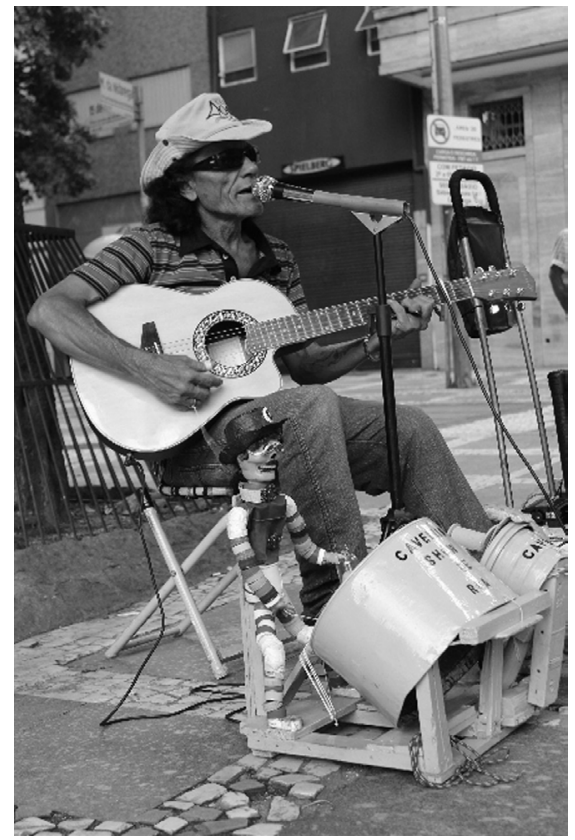


Figura 7. Plano médio a partir do rés-do-chão sobre a face noroeste da Praça da Sé (abril 2011)

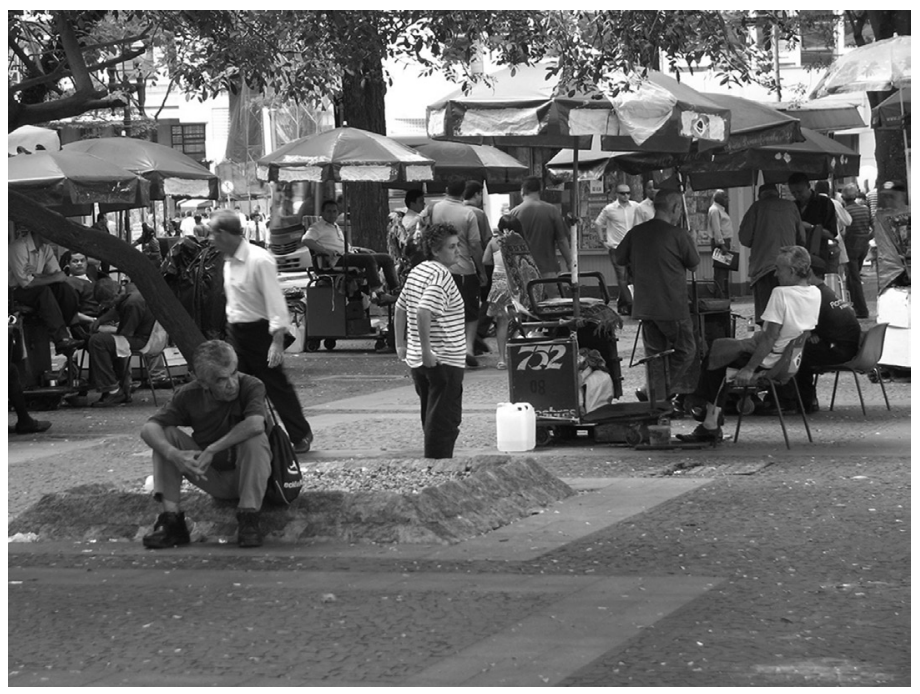

[C Fraya Frehse; Fonte: Coleção Particular]

Figura 8. Plano médio a partir do terraço de um edifício bancário na direção oeste do extremo norte da Praça da Sé (abril 2011)

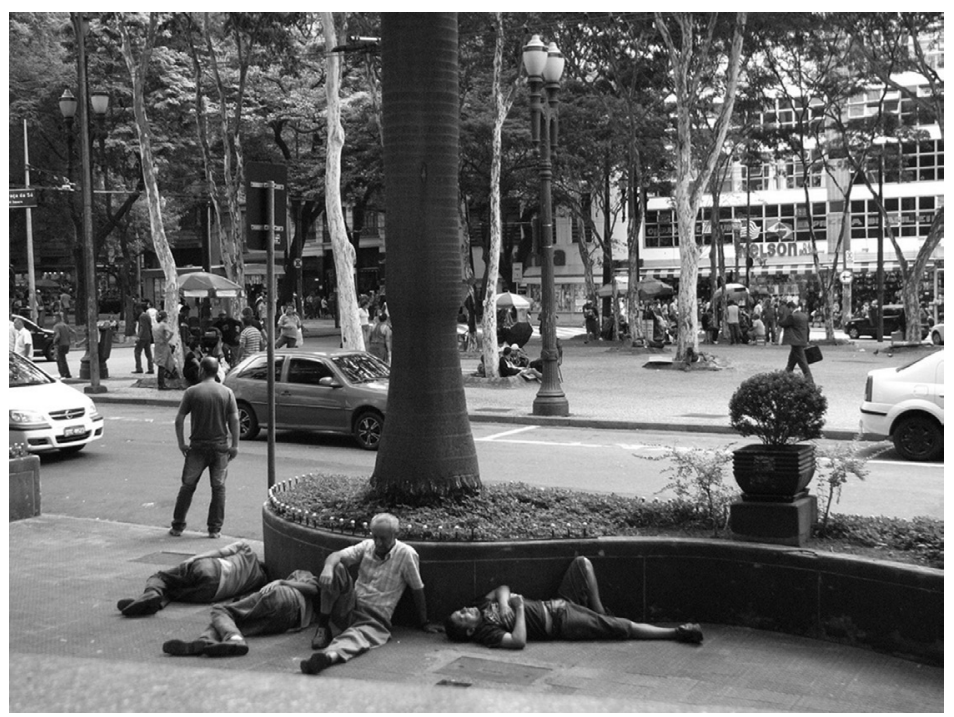

[C Fraya Frehse; Fonte: Coleção Particular] 
Quer se trate de artistas ou artesãos, de vendedores ou pregadores de rua, mas também dos autodenominados moradores de rua, de aposentados ou desempregados de idades e gêneros variados: em meio ao trânsito acelerado de transeuntes, automóveis e meios públicos de transporte, esses pedestres de procedências socioeconômicas, socioculturais e socioespaciais diversas compartilham sem saber, querendo ou não, um conjunto definido de técnicas corporais e um ritmo corporal. Eles ali permanecem fisicamente em regularidade linear, seja para fins de sobrevivência econômica ou em prol de laços de sociabilidade que ali se reativam dia a dia. No momento em que, às 19h, as lojas baixam as portas e os albergues públicos já abriram as suas, aí não apenas os transeuntes, mas também a pletora de não-transeuntes desaparecem das ruas e praças públicas do centro histórico paulistano. Só quem precisa ou quer dormir ali, deixa-se fisicamente com regularidade nas vias e logradouros também durante a noite.

Quando, à luz desse cenário empírico, o foco analítico recai sobre as regras de interação social que tornam historicamente possível a reprodução dessa sociedade da rua no perímetro urbanizado mais antigo de São Paulo nos horários comerciais dos dias úteis, aí há como reconhecer que repetições cíclicas condicionam dia a dia o ritmo linear da permanência física regular ali. O cansaço faz do tablado da Praça da Sé um banco, a mureta ou uma escultura viram camas. Já para fazer frente à fome que aperta, nada como os ingredientes necessários angariados via compra ou esmola, e um pequeno fogaréu de camping sobre a mesma mureta. Os policiais bem perto dali não parecem se incomodar...

Em suma, aquilo que Lefebvre ([1974] 2000, p. 23-24, passim) concebe como uso do espaço de natureza corporal, qualitativa, condicionado por ritmos cíclicos, é fato nesses espaços públicos. E isso em meio à contundência de ritmos corporais lineares.

Tais dados empíricos reforçam em mim a impressão de que, ao menos nos dias úteis, essa dialética rítmica constitui um elemento essencial das ruas e praças públicas centrais de São Paulo. Ali e então o transeunte certamente não é hegemônico... Na sociedade da rua do centro histórico de São Paulo desta segunda década do século 21 repetições lineares e cíclicas coexistem, em aparente absoluta indiferença em relação a pressões disciplinadoras periódicas do poder público e da polícia que, no atual contexto de globalização econômica, vão voluntária ou involuntariamente ao encontro de uma concepção política específica, própria da chamada gentrificação - requalificação física de áreas específicas das cidades, em particular os núcleos com a urbanização historicamente mais antiga, para fins turísticos, de moradia ou de consumo por 
grupos de maior poder aquisitivo (para uma síntese do debate sobre o tema, ver Rubino, 2009).

No intuito de explanar a contundência "comercial e útil" dessa conjuntura de ritmos, Lefebvre oferece uma resposta: "todo ritmo implica a relação de um tempo com um espaço, um tempo localizado ou, se preferirmos, um lugar temporalizado. O ritmo é sempre ligado a tal ou qual local, a seu local" (Lefebvre, 1992, p. 99). Datar historicamente a regra de comportamento corporal da permanência física regular nas ruas e praças centrais paulistanas do presente, torna possível reconhecer a sua intrigante semelhança com modos de comportamento corporal que prevaleciam dia a dia nas vias e largos da São Paulo escravista. E isso, mesmo que os pedestres hoje em dia sejam evidentemente bem diversos, assim como as mediações socioeconômicas, técnicas e socioculturais que tornam historicamente possível a sua convivência social nas ruas e praças centrais do centro paulistano.

Com base nessas constatações ritmanalíticas de natureza regressivoprogressiva, espero que esteja evidente o porquê do título deste ensaio. A profundidade histórica dos ritmos corporais dos não-transeuntes paulistanos remete a um processo de urbanização que, ao menos no nível do cotidiano "comercial e útil" nos e pelos espaços públicos do centro paulistano, é condicionado de modo contundente por ritmos pré-modernos. Sob esse prisma, a cidade se transforma sobretudo à medida que os seus espaços públicos historicamente centrais se reproduzem dia a dia. E isso em meio ao acúmulo periódico de providências político-administrativas e urbanísticas supostamente inovadoras, no que se refere ao combate justamente às regras de comportamento corporal que medeiam a permanência física regular dos não-transeuntes nesses espaços.

\section{Considerações finais}

Assim, é possível evidenciar de maneira sintética a existência de duas contribuições metodológicas definidas da ritmanálise para a questão da mudança social na vida cotidiana, no espaço urbano contemporâneo. A abordagem:

- aponta para a relevância cognitiva do estranhamento antropológico e histórico dos ritmos corporais tanto do pesquisador quanto dos pedestres que o envolvem nas ruas e praças públicas, quando o que importa é apreender analiticamente possibilidades históricas implícitas no cotidiano urbano;

- convida a sociologia a enfrentar um objeto investigativo peculiar: a historicidade das regras de comportamento corporal em espaços públicos urbanos. 
Trata-se de dois aspectos que os estudos urbanos tributários de conceituações sociológicas pouco enfatizam, por referência ao Brasil dos dias de hoje. Apreender o porquê dessa parcimônia, contudo, escaparia aos limites deste ensaio (Frehse, 2013; 2014).

\section{Referências}

AJZENBERG, Armand. À partir d'Henri Lefebvre, vers un mode de production écologiste. Paris, 1994, mimeo. (Comunicação no Colóquio "Traces de futurs. Henri Lefebvre: le possible et le quotidien")

BACHELARD, Gaston. La dialectique de la durée. Paris: Presses universitaires de France, 1950.

BAPTISTA, Pedro. O filósofo fantasma: Lúcio Pinheiro dos Santos. Sintra: Zéfiro, 2010.

CORPET, Olivier, PAQUOT, Thierry. Henri Lefebvre. In: Olivier Corpet, Thierry Paquot. Entrevistas ao Le Monde: idéias contemporâneas. São Paulo: Ática, 1989 [1. ed. 1972]. p. 131-137.

COSTA, Sérgio. Teoria por adição. In: Heloisa T. de Souza Martins (org.). Horizontes das ciências sociais: Sociologia. São Paulo: Anpocs, 2010. p. 25-51.

ELDEN, Stuart. Rhythmanalysis: An Introduction. In: Henri Lefebvre. Elements of rhythmanalysis. London: Continuum, 2004. p. vii-xv.

FORTUNA, Carlos. (Micro)territorialidades: metáfora dissidente do social.Terr@ Plural, v. 6, n. 2, p. 199-214, $2012<10.5212$ /TerraPlural.v.6i2.0001>.

FREHSE, Fraya. A sociedade da rua em São Paulo: a cidade fora dos muros. Projeto de Pesquisa. São Paulo: Departamento de Sociologia da Universidade de São Paulo, 2011, mimeo.

FREHSE, Fraya. Ô da rua! São Paulo: Edusp, 2011b.

FREHSE, Fraya. Arua no Brasil em questão (etnográfica). Anuário Antropológico/2012, v. 38, n. 2, 2013, p. 99-129.

FREHSE, Fraya. For Difference "in and through" São Paulo: the regressive-progressive method. In: Lukasz Stanek et al. (orgs.). Urban revolution now. Surrey: Ashgate, 2014. p. 243-62.

GOFFMAN, Erving. Interaction ritual. Garden City: Anchor Books, 1967.

LEFEBVRE, Henri. Critique de la vie quotidienne. v. 1. Paris: L'Arche Éditeur, 1958 [1 $1^{\text {a }}$ edição 1947].

LEFEBVRE, Henri. Critique de la vie quotidienne. v. 2. Paris: L'Arche Éditeur, 1961.

LEFEBVRE, Henri. La vie quotidienne dans le monde moderne. Paris: Gallimard, 1968.

LEFEBVRE, Henri. La révolution urbaine. Paris: Gallimard, 1970.

LEFEBVRE, Henri. Sociologie de Marx. Paris: PUF, 1974 [1. ed. 1966]. 
LEFEBVRE, Henri. Vers le cybernanthrope. Paris: Denoël/Gonthier, 1967-1971.

LEFEBVRE, Henri. La présence et l'absence. Paris: Casterman, 1980.

LEFEBVRE, Henri. Critique de la vie quotidienne. v. 3. Paris: L'Arche Éditeur, 1981.

LEFEBVRE, Henri. Lógica formal, lógica dialética. 4. ed. Rio de Janeiro: Civilização Brasileira, 1983 [orig. fr. 1947].

LEFEBVRE, Henri. La production de l'espace. 3a. ed. Paris: Anthropos, 2000 [1. ed. $1974]$.

LEFEBVRE, Henri. Perspectives de sociologie rurale [1953]. In: Henri Lefebvre. $D u$ rural à l'urbain. 2. ed. Paris: Anthropos, 2001. p. 63-78.

LEFEBVRE, Henri, REGULIER, Cathérine. Le projet rythmanalytique. Communications, 41, p. 191-199, $1985<10.3406 /$ comm.1985.1616>.

LEFEBVRE, Henri, REGULIER, Cathérine. Rythmanalyses des villes méditerranéennes [1. ed. 1986]. In: Henri Lefebvre. Éléments de rythmanalyse. Paris: Syllepse, 1992. p. 97-109.

LEFEBVRE, Henri. Éléments de rythmanalyse. Paris: Syllepse, 1992.

LEFEBVRE, Henri. Éléments of Rhythmanalysis. London/New York: Continuum, 2004.

MARX, Karl; ENGELS, Friedrich. I. Feuerbach. In: Karl Marx; Friedrich Engels. Die deutsche Ideologie. Berlin: Dietz, 1960 [1. ed. 1932]. p. 17-77.

MAUSS, Marcel. Les techniques du corps [1936]. In: Marcel Mauss. Sociologie et anthropologie. Paris: Quadrige/Puf, 1997 [1. ed. 1950]. p. 363-386.

MEYER, Kurt. Rhythms, Streets, Cities. In: Kanishka Goonewardena et al. (orgs.). Space, difference, everyday life. New York: Routledge, 2008. p. 147-160.

RUBINO, Silvana. Enobrecimento urbano. In: Carlos Fortuna, Rogerio Proença Leite (orgs.). Plural de cidade. Coimbra: CES/Almedina, 2009. p. 25-40.

SCHMID, Christian. Stadt, Raum und Gesellschaft. München: Franz Steiner Verlag, 2005.

Recebido em: 23 out. 2015

Aprovado em: 14 mar. 2016

Autora correspondente:

Fraya Frehse

Departamento de Sociologia, Universidade de São Paulo

Avenida Prof. Luciano Gualberto, 315, s. 8 (ala nova)

Cidade Universitária, Butantã

05508-010 São Paulo, SP, Brasil 